The specimen was seven and a half inches in length; the constricted portion, that is, the portion leaving the cecum and surrounding the ileum, was four and a half inches in length; the free portion three inches long and one and one-half inches in diameter and forcibly distended by gas. It was entirely devoid of mesentery and its canal was pervious throughout. The portion surrounding the ileum passed from behind forward and lay beneath the serous coat; i.e., it was between the serous and muscular coats. The trouble evidently commenced in the appendix, and as the portion surrounding the small intestine became infiamed and swollen, it compressed the muscular coat of that portion of the intestine which it surrounded, gradually causing the obstruction.

Greves reports a case of intestinal obstruction due to the appendix, in the London Lancet of Dec. 6, 1884. In his case the free end of the appendix had become attached to the peritoneal wall, the body of the appendix forming an arch, under which a loop of the small intestine had passed and became strangulated.

Nicolaysen reported a case in the British Medical Journal of July 23, 1892. In this case the appendix had been previously inflamed and the mesentery of the appendix had become adherent to a portion of the small intestine; this afterward produced a volvulus.

I do not know of any similar case to the one I have described being reported by any writer, and this adds one more reason why the appendix should always be considered when the peristaltic action of the intestinal canal is interfered with.

Note.--The specimen was exhibited before the Detroit Medical and Library Association on Bept. 13, 1897.

\section{STUDIES OF SOME FACIAL BONES.}

Presented to the Section on Laryngology and Otology, at the Fortyeighth Annual Meeting of the American Medical Association, held at Philadelphia, Pa., June 1-4, 1897.

BY MATTHEW H. CRYER, M.D.

$$
\text { PHILADELPHIA, PA. }
$$

The experience gained in a hospital devoted to the treatment of diseases of the jaws, face and associated parts, demonstrated to me several years ago that the text-book descriptions of the anatomy of these parts did not correspond closely with numerous observed clinical facts. To clear up the contradictory elements of this subject, I began, some four years ago, to make serial sections of such skulls as I could gain possession of, in all, numbering some hundreds.

These studies, some of which have been published, demonstrated that many of the printed, or text-book, description of the parts included, contained matter entirely at variance with observed facts.

Finding these printed errors so numerous in the anatomy relating to the parts embraced in the field of oral surgery, it was natural to carry the observations to more distant parts, and I found in them, as will be shown, that errors of description are far from uncommon in the works on anatomy relating to the nasal chamber.

When there is lack of bi-lateral symmetry of the part of the bony anatomy of the head, it is commonly associated with other marks of lack of bi-lateral symmetry, and vice versa; that is, if observation shows the dental arches, the palatal processes, and inferior maxillary bone to be bi-laterally symmetrical, bilateral symmetry usually exists in all of the bones, and so on.
Figure 1 shows an under view of a skull almost anatomically perfect, except that the extermal plates of the pterygoid process are not quite alike upon both sides, and there is a slight difference in the zygo-

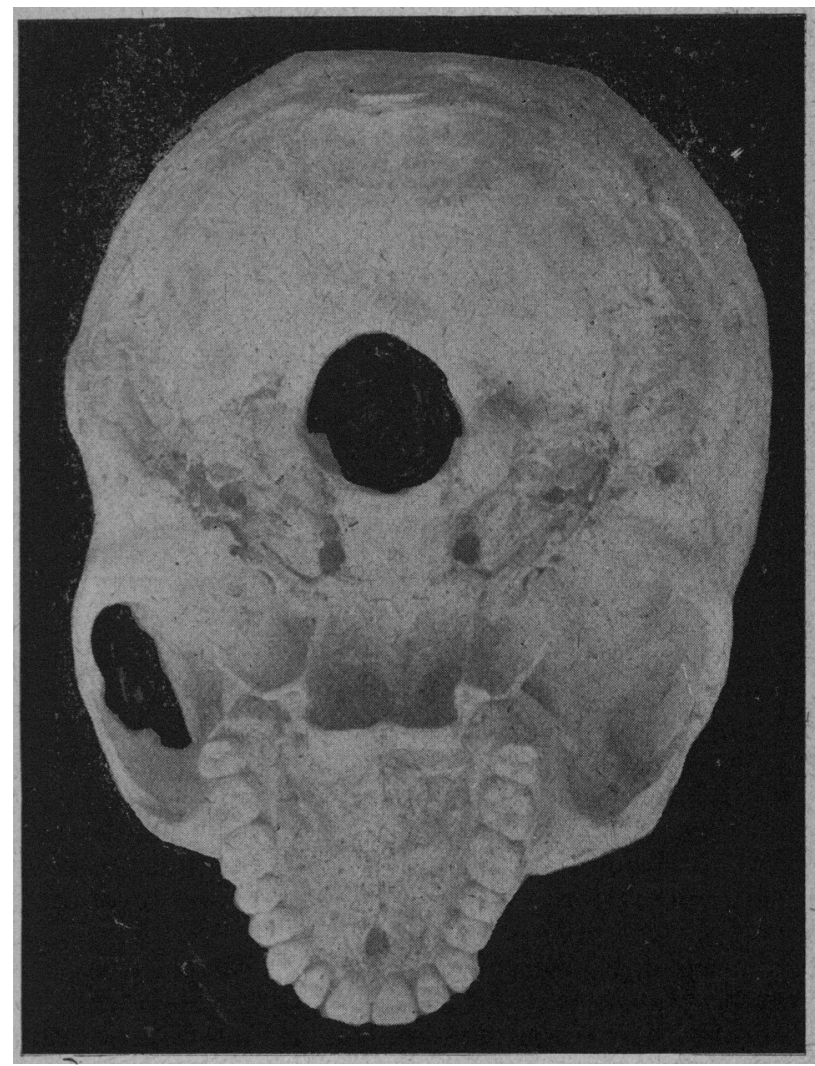

Figure 1.

matic arches of the two sides. The skull is tilted slightly, so that the sides do not appear as symmetrical as they really are.

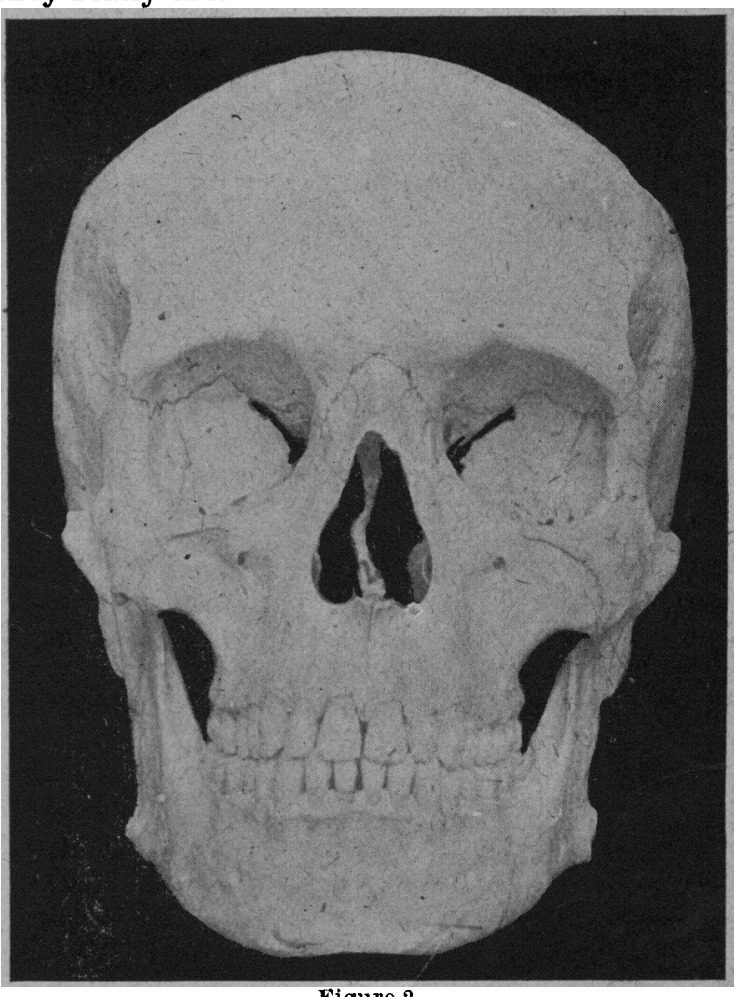

Figure 2. 
Figure 2. Same skull gives a front view, the only lack of symmetry being a slight deviation of the septum of the nose. The bulla ethmoidalis of the left side is somewhat larger than that of the right, and the nasal septum is deflected from that side. It is often said that the septum is never straight. This, however, is an error, for I have many specimens in which it is perfectly vertical.

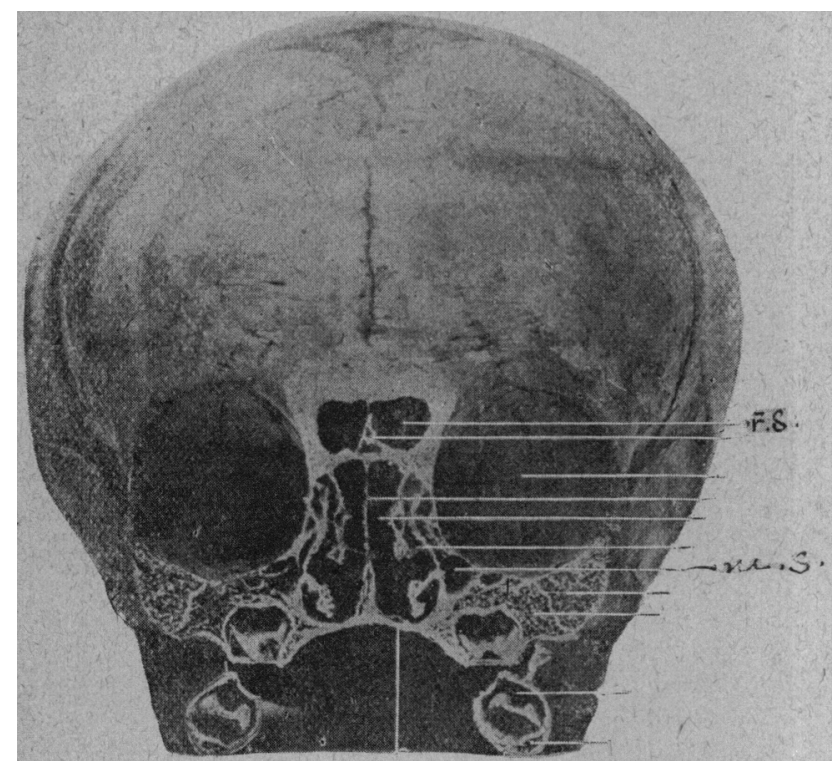

Figure 4.

Figure 3. The first of this series is a vertical section through the facial bones of a seven months fetus. The specimen is almost perfectly symmetrical, bi-laterally. It shows the beginning of the development of the maxillary sinus, M. S. The line of junction between the superior maxillary and malar bones is

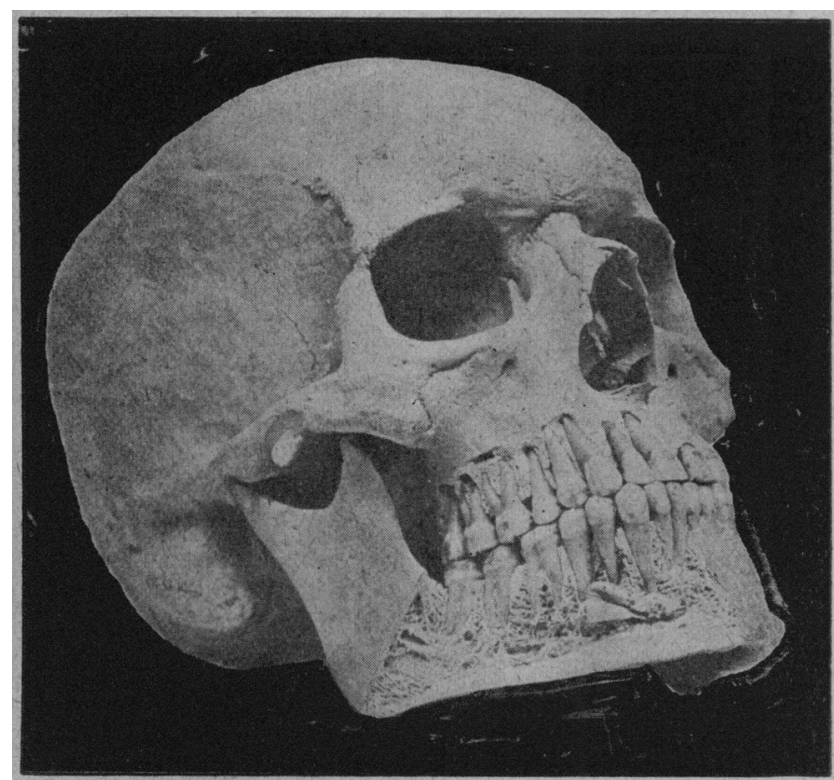

Figure 3.

well-marked, as is also the infra-orbital canal, lying beside the developing antrum. Attention is called to the appearance of this canal in section. It looks like a cross-section of a tube. Note the point of the nasal wall at which the invagination, which is to form the future sinus, begins; it is at a higher level than the floor of the orbit. The direction of the developing sinus is downward and outward.

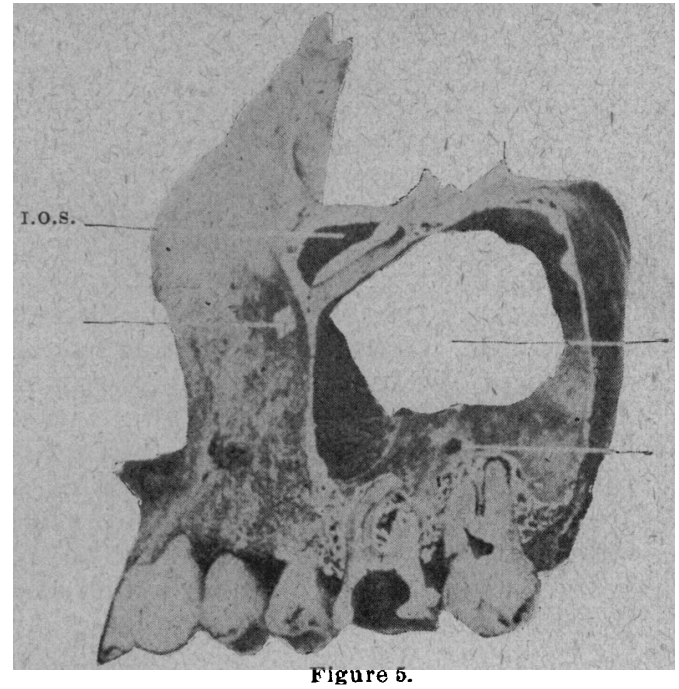

Figure 4 represents the antero-lateral view of the skull, giving a general idea of the several external bones of one side of the face and head. The occlusion of the upper and lower teeth is almost normal. It shows the relations of the bones, of which we are to speak, to the other external bones. The outer surface of the lateral and anterior wall of the antrum is shown, the teeth having been denuded of the exter-

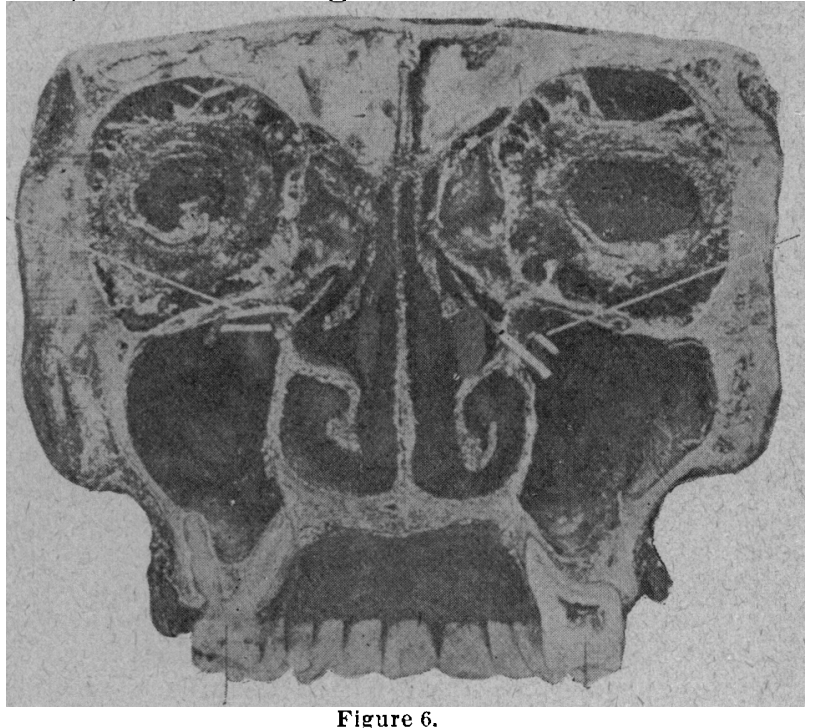

nal plate of the alveolar process. The maxillary sinus has been opened immediately over the roots of the first, second and third molars, showing, in this case, how thin the bone is between the roots of the teeth and the floor of the sinus. It is also very thin over the points of the roots of the cuspid and first and second bicuspids. I wish to draw attention to the position of the infra-orbital foramen, which is usually

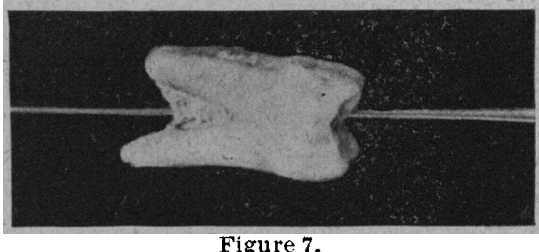

described as the termination of the infra-orbital canal, which passes through the solid portion of the infra- 
orbital ridge to the groove in the floor of the orbit.|the passageway for the infra-orbital vessels and Several of the figures will show that this canal often nerves, a distinct tube and not a passage channeled passes diagonally through the sinus in the shape of through the bone. The sinus in this case is seen

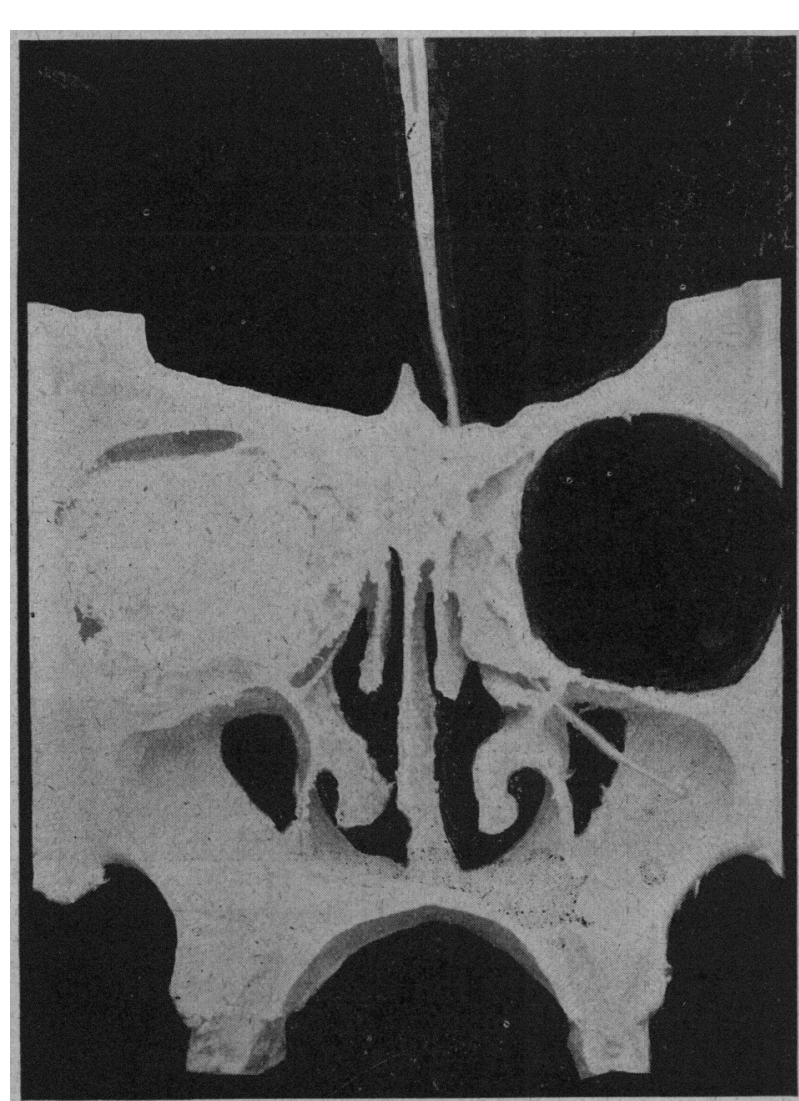
extending into the infra-orbital ridge, forming what might be fitly termed an infra-orbital sinus. (I.O.S.)

The relations of the roots of the molars to the floor

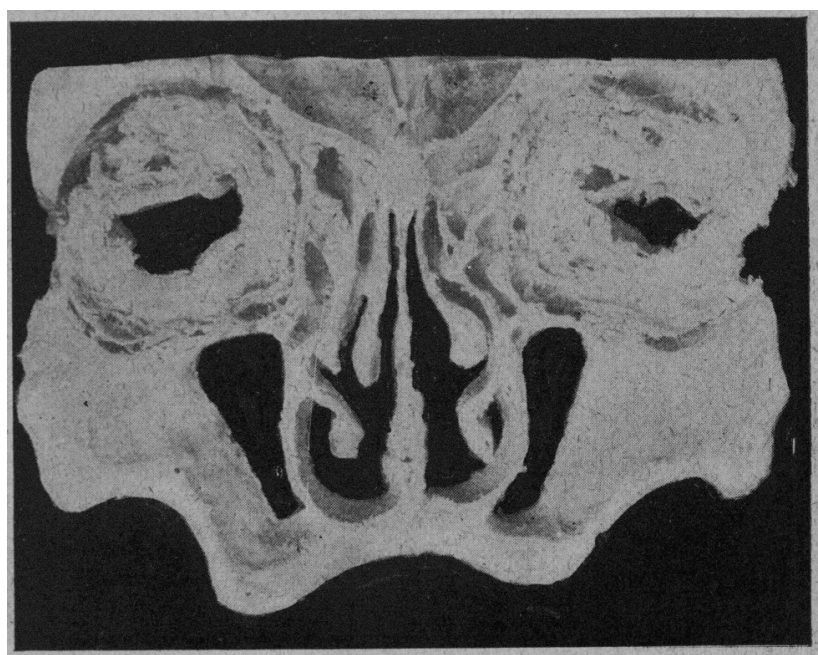

Figure 10.

of the antrum is an interesting feature of this section. In consequence of the death and decomposition of the pulp of a molar tooth, there has been, first, irritation and a constructive periostitis upon the floor of the antrum, which has caused a thickening of the bone over the apex of the root. At a later period,

Figure 8.

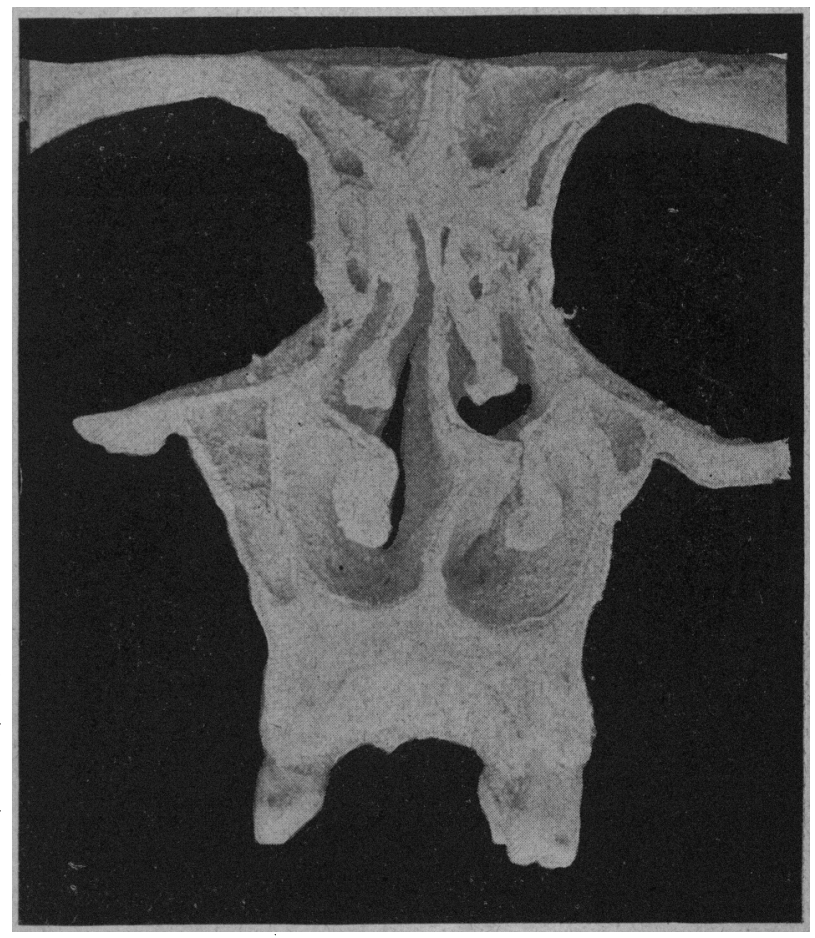

Figure 11

Figure 9.

suppurative inflummation has occurred, an ubscess has formed and perforated the floor of the antrum.

Figure $t i$ shows the floor of the antrum extending

Figure 5 shows a vertical section made through the upper portion of the right superior maxillary bone. In the upper front portion of the antrum is shown

between the roots of the molar teeth, a condition much more common among the white races than 
among the negroes, according to my observation. passed through the foramen of exit from the frontal Abscess upon the roots of such teeth may cause sinus, the unobstructed path of which is directly into perforation of the floor of the antrum, and the ex- the antrum. I pointed out two years ago how comtraction of a tooth would almost certainly be accom- mon it was to find this condition, one in which effupanied by fracture of the floor of the sinus. Note, sions, or secretions, from the frontal sinus would find also, that regarding the antrum as a cuboidal cavity, their way into the antrum.

its exit is at its upper and inner angle. Note, also, the angle of the uncinate process. This is the usual

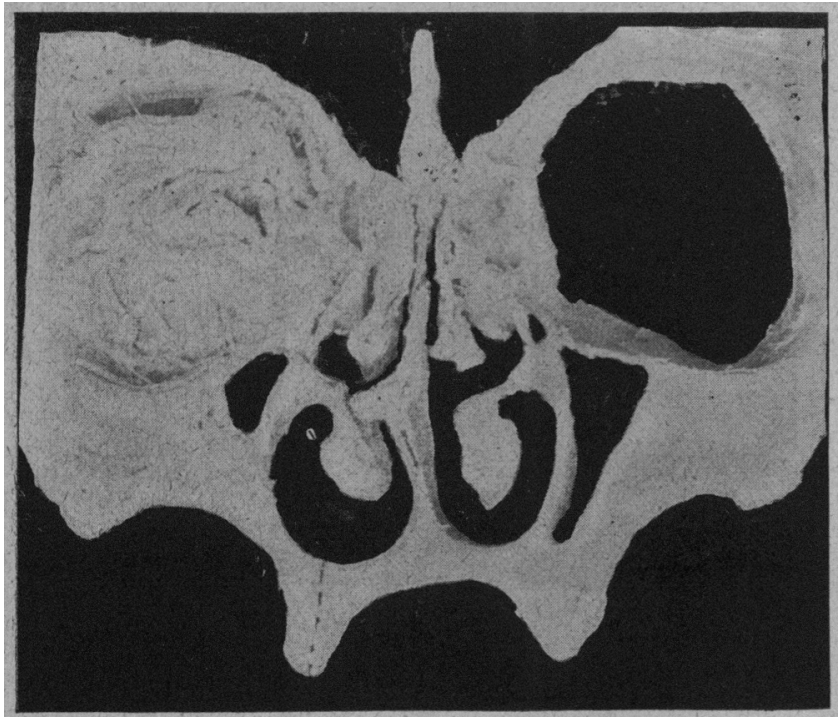

Figure 12.-Looking backward.

condition in all the skulls I have cut. You will see, therefore, that it is a mechanical impossibility to pass a probe from the anterior naris through the foramen of antral exit in normal bone.

Figure 7 is a tooth which has been drilled through while in the mouth, the operator supposing his drill was passing up the palatal root of the tooth, instead of whioh it passed through the base of the crown, the

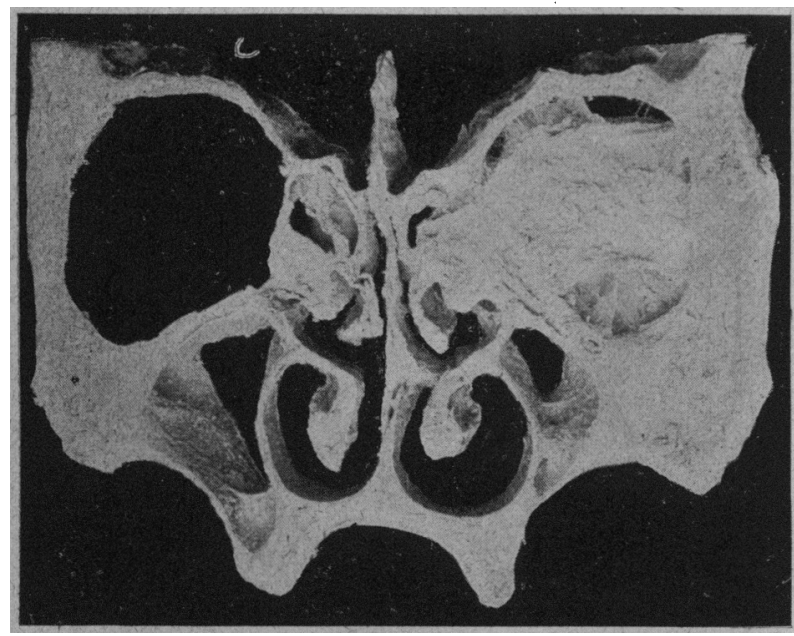

Figure 13.-Looking forward.

pulp chamber, the alveolar process, and into the maxillary sinus. It will be observed that in extracting it a portion of the floor of the antrum has been brought away with the tooth. The patient was suffering, at the time of extracting, from empyema of the antrum.

Figure 8 is a section of a negro skull. Note the greater thickness of the floor of the antrum. The point of special interest in this specimen is the probe,
Figure 9 is introduced to show the vertical septa, which frequently cross the antrum from side to side, springing from its floor, and dividing the lower por-

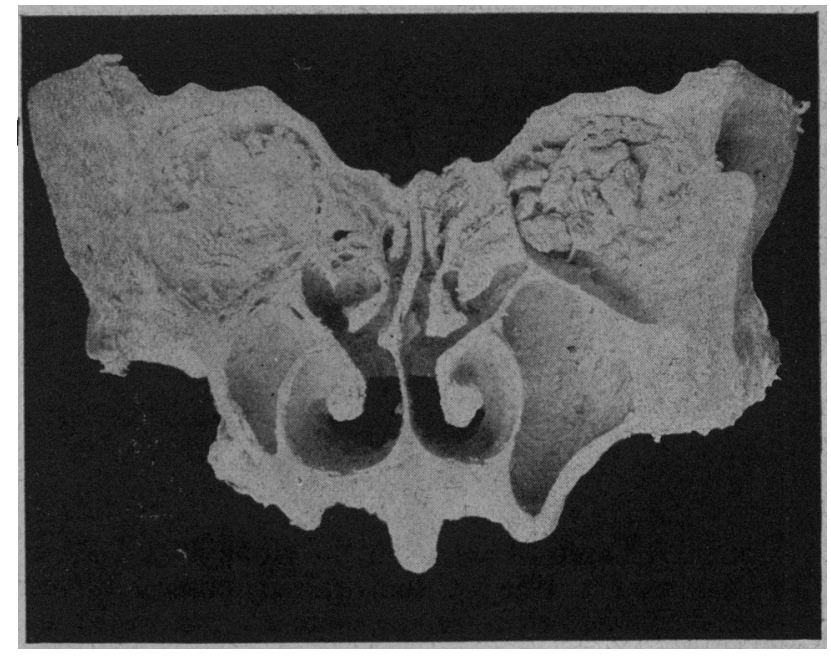

Figure 14,-Looking forward.

tion of the cavity into semi-chambers. Septa of two sizes are shown in the right and left sides. Note. also, how the development of the antrum has reduced the thickness of its walls to thin boundary layers. Note the projection of the bulla ethmoidalis upon one side; it is common to find a deviation of the nasal

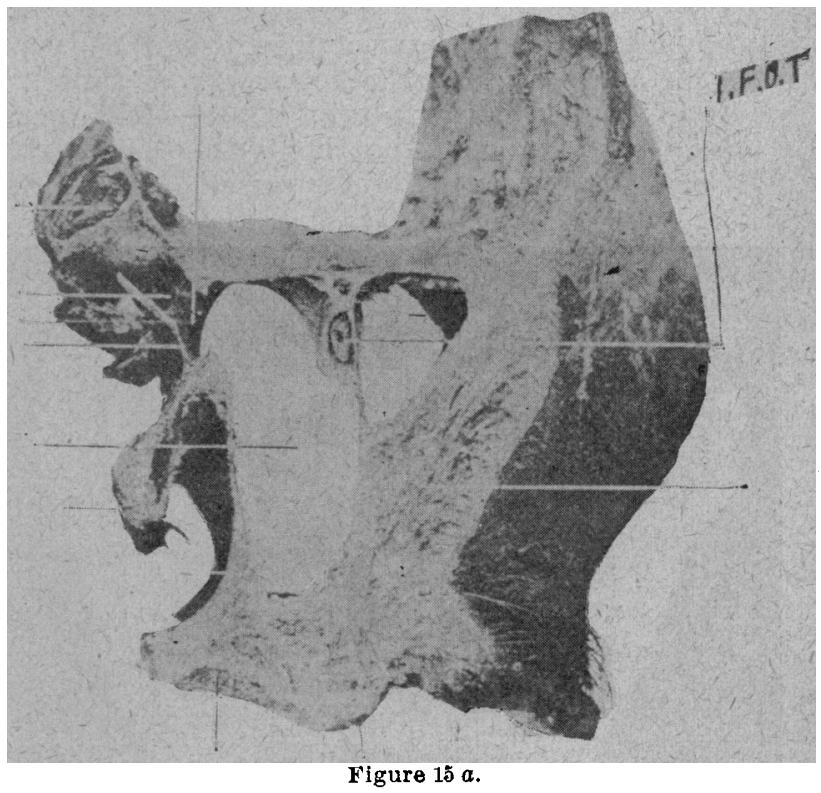

septum from that side in such cases, as may be seen in some of the following figures; adenoid growths are also common.

Figure 10 exhibits a condition occasionally met with, the floor of the antrum dipping inward, and partially under the floor of the nose; it will be noted, from the axis of the alveolar process, that in this case the sinus could be drained directly from the palatal aspect of the mouth. 
Figure 11 exhibits an entire lack of symmetry between the nasal fossæ and the sinus of the right and left sides, the inferior meatus of one side being closed anteriorly by the deflected nasal septum.

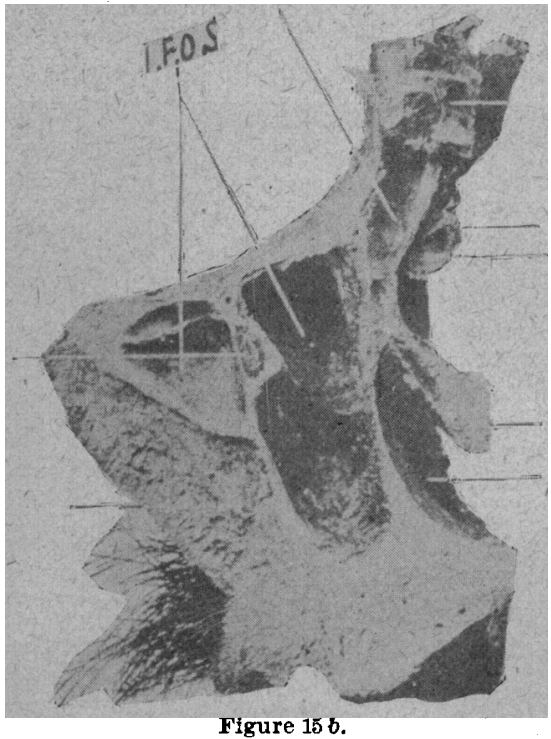

Figures 12 and 13 are from the same head. It will be noted that a line, or instrument, passed through the axis of the alveolar process of the right side would perforate the floor of the nostril, instead of the floor of the antrum.

Figure 14 is from the same subject, posterior to the

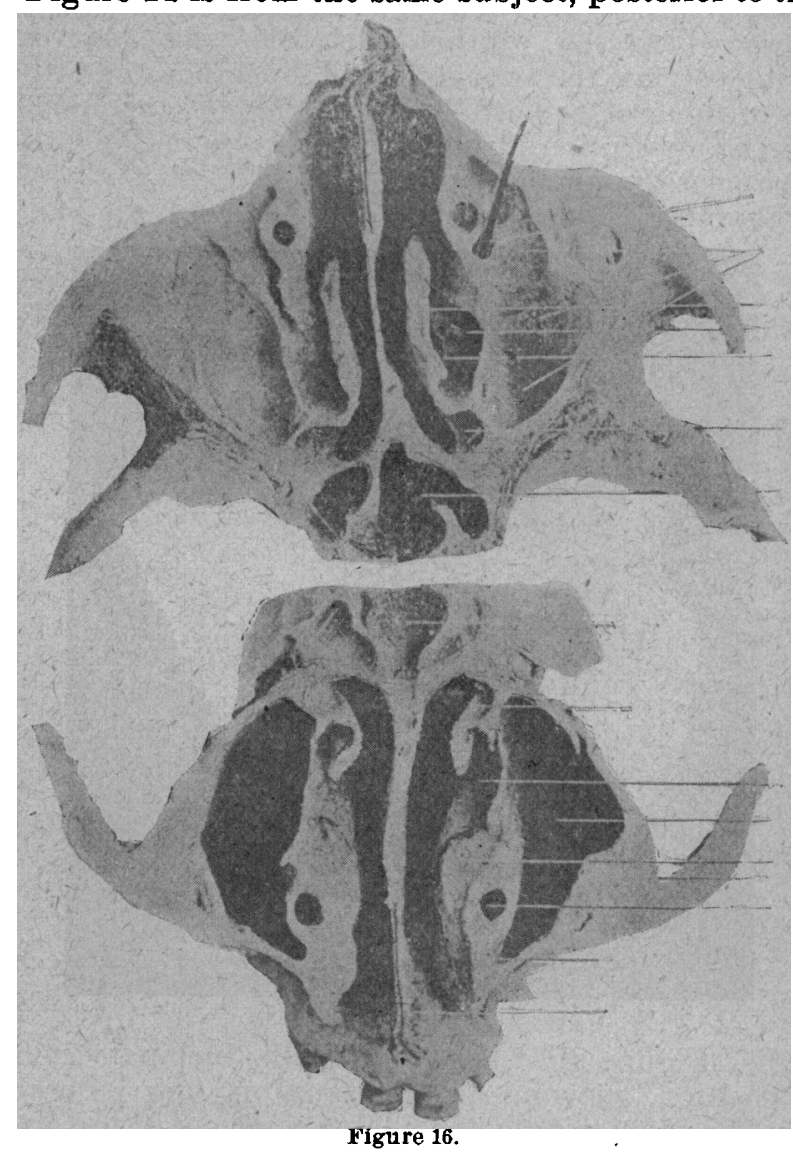

other sections; the lack of symmetry of the antra is well marked, the more prominent side of alveolar process being associated with the larger antrum.

Figure 15 shows well the exit from the antrum at its upper and inner portion, together with the direction of the hiatus semilunaris. Note, also, the section of the infra-orbital tube. The second figure of the cut shows the division of the sinus, which I have called the infra-orbital. At the right upper corner is the normal opening of the maxillary sinus, leading into the hiatus semilunaris, which is bounded below

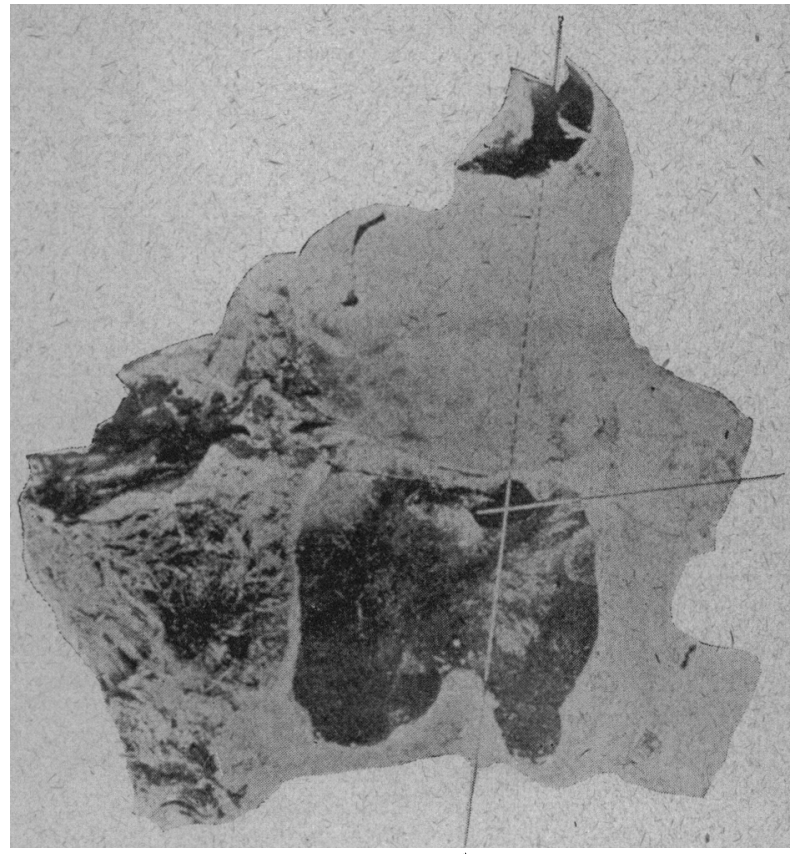

Figure 17

and to the inner side by the uncinate process, to outer side by the wall of the sinus, and above by the bulla ethmoidalis. This last named rounded projection contains the middle ethmoidal cells; they vary in size in different skulls, and very often in the same skull. I believe this structure to be an important factor in

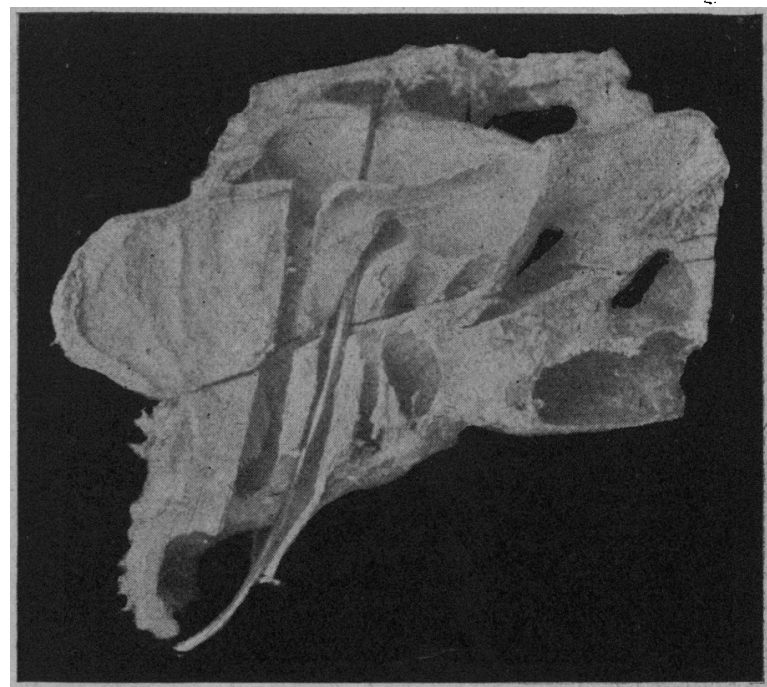

Figure 18.

causing various diseases of this region, including those of the maxillary and frontal sinuses.

Figure 16 shows upper and lower views of a transverse section passing near the roof of the antra, where it is noted that the place of exit from the antra is in the roof.

Figure 17 shows by the probes passed through the 
passages, the relative directions of the exits from the maxillary and the frontal sinuses.

Figure 18. Where there are two infundibula leading from the frontal sinus to the antrum, the probe passing upward into the frontal sinus passes through the infundibulum.

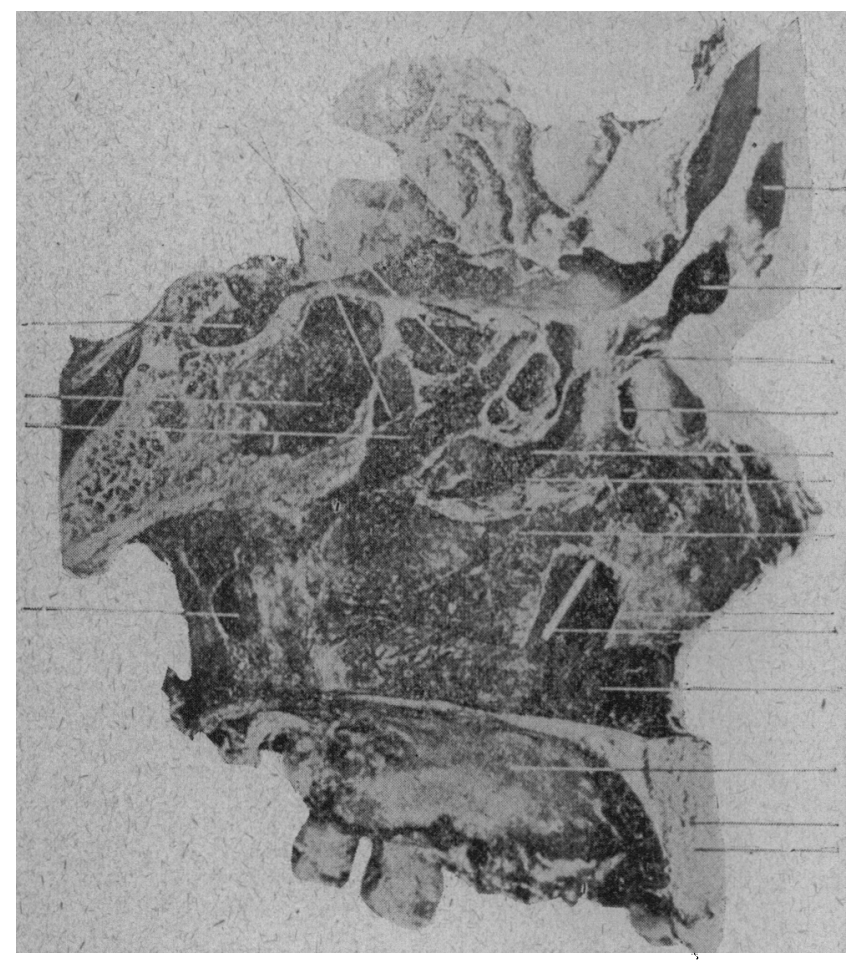

Figure 19.

Figure 19 shows the outer nasal walls, and the normal relation of the bulla ethmoidalis with the uncinate process, together with the nasal entrance to the maxillary sinus.

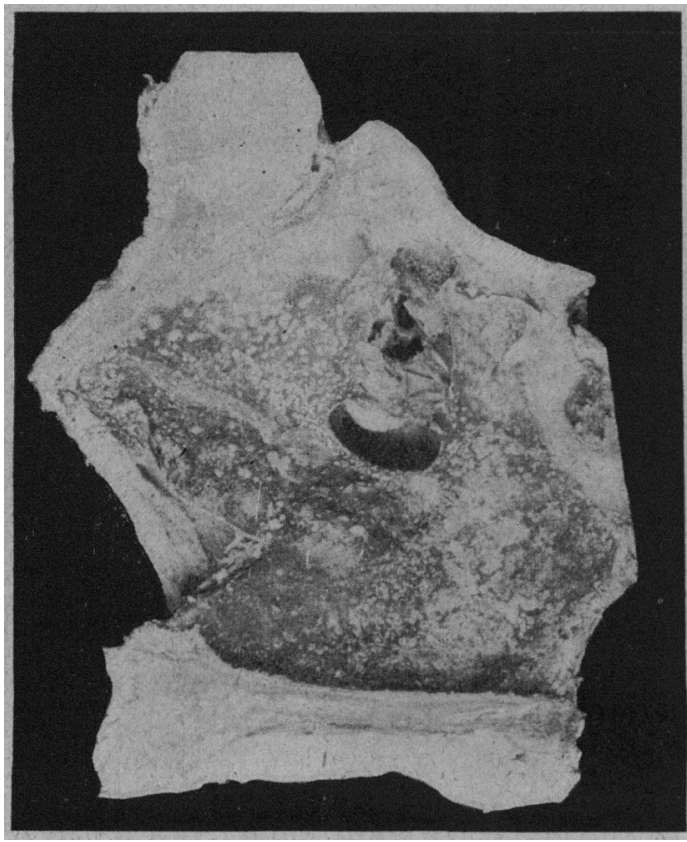

Figure $20 a$.

Figure 20 shows abnormal perforation of the inner wall of the antrum. In consequence of the enlargement or distension of the chambers of the bulla eth. moidalis, there has been occlusion of the hiatus semi- lunaris. Presumably the contents of the antrum have made for themselves an escape, by forming a false foramen. In Figure $20 a$, the septum is in place. It will be seen that there is an opening in it, exposing to view the bulla and its ethmoidal cells. This absorption of the portion of the septum has been caused by pressure of the deflected septum, and the

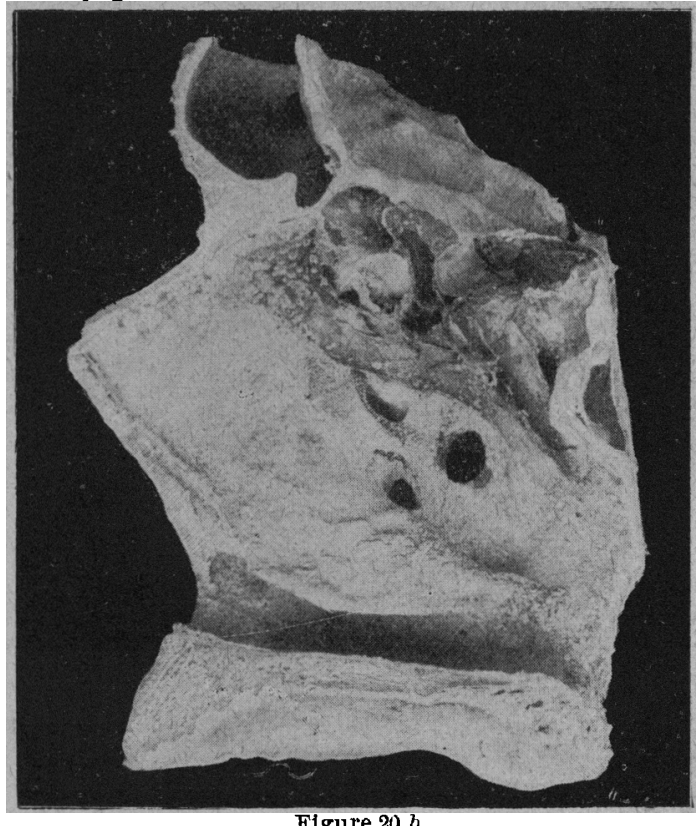

Figure 21) $b$.

enlargement of the bulla ethmoidalis. Figure $20 b$ shows where the septum has been removed, exposing to view the two abnormal openings, and the loss of the greater portion of the middle turbinated bone by absorption through the pressure of the bulla down near the uncinate process.

Figure 21 is taken from the left side of the same

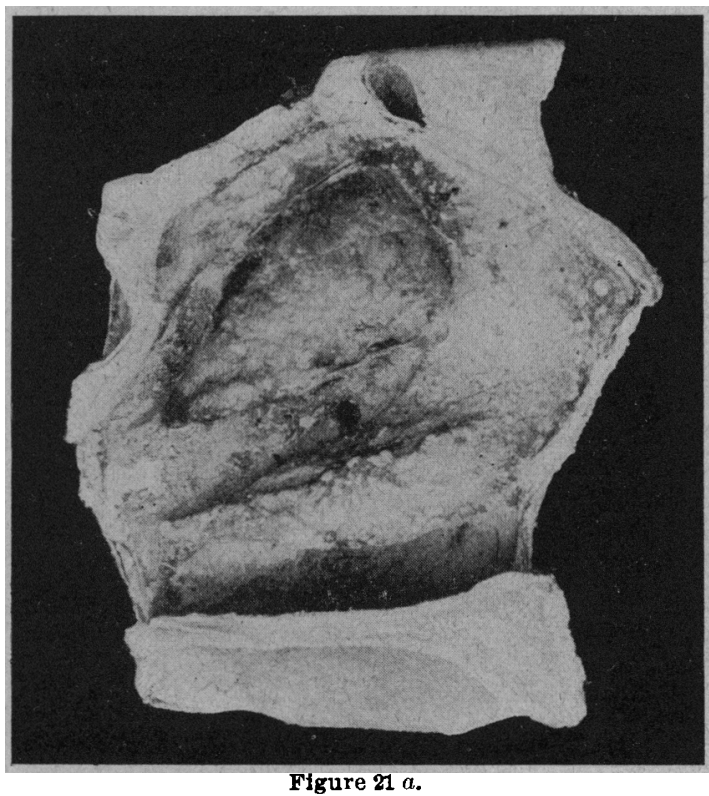

skull. Figure $21 b$ has the middle turbinate bone in position, showing an abnormal opening. Figure $21 a$ has the middle turbinate bone cut loose and turned upward, exposing the bulla extending downward and closing the hiatus semilunaris, the passageway for the fluids from the frontal and maxillary sinuses, also from the anterior and middle ethmoidal 
cells. This closure has been the cause of the abnormal the axis of the molar teeth. The relation of the ends opening from the maxillary sinus.

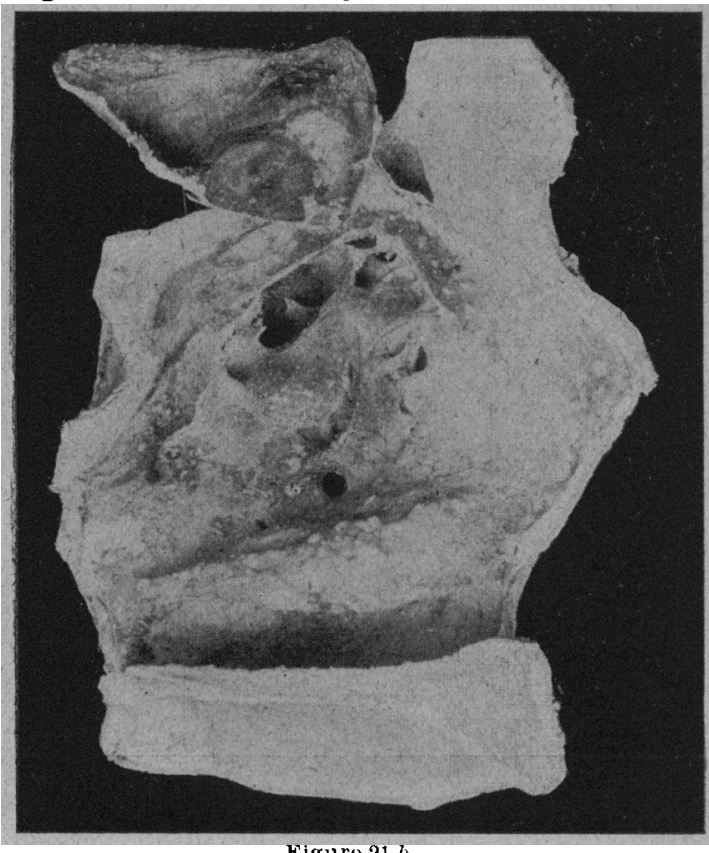

Figure $21 b$,

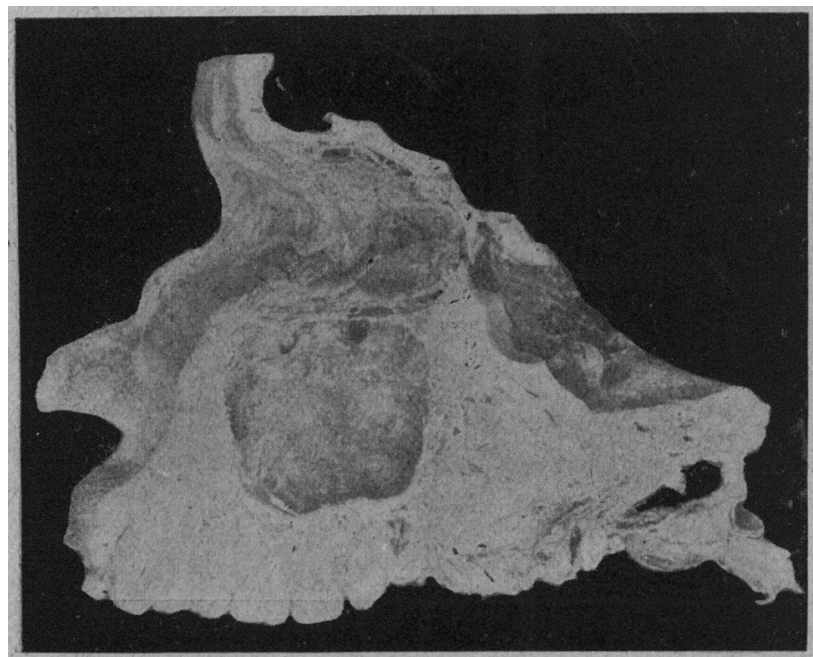

Figure 22,-Right.

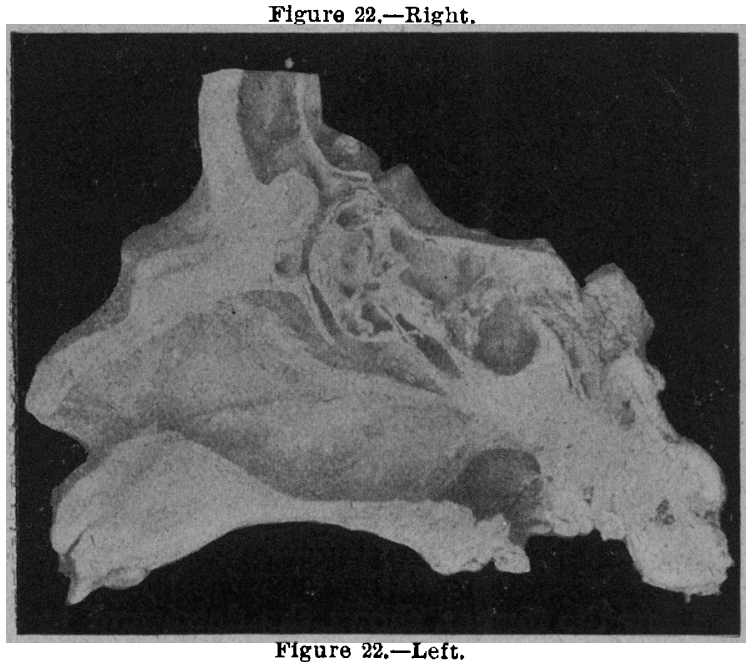

Figure 22. The right picture shows the outer wall is shown. The special feature of this cut is the of antrum removed, the section passing almost through $\mid$ double opening leading from the antrum. of the roots of these teeth with the floor of the antrum
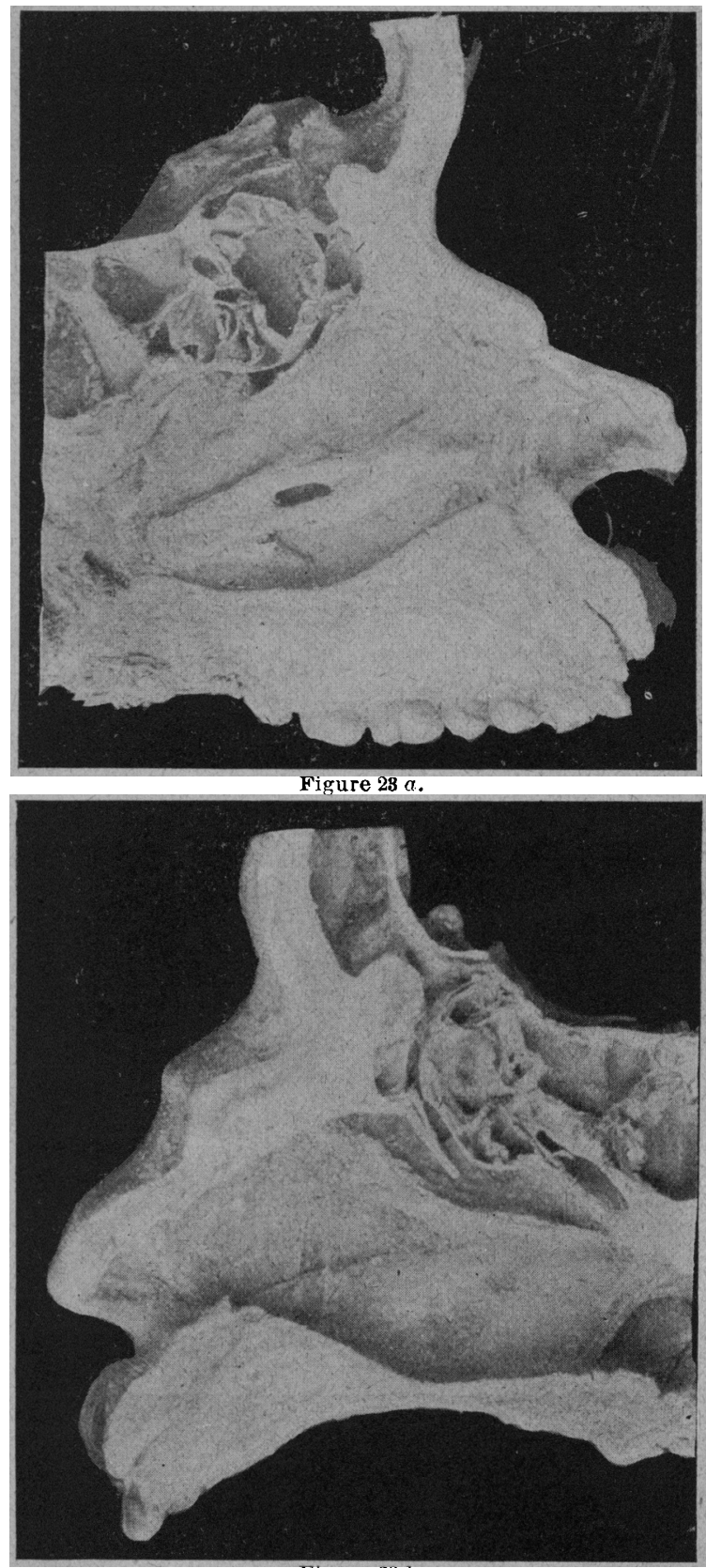

Figure $23 b$.

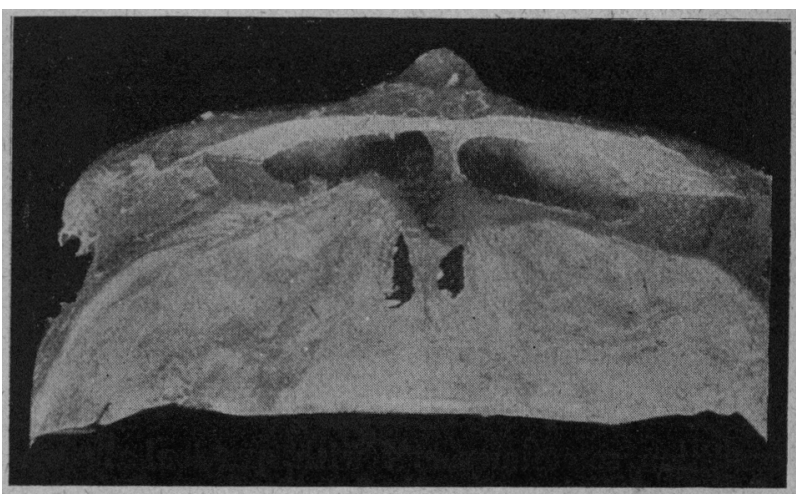

Figure 24. 
The left picture is made from a section cut immediately within the nasal cavity of the same subject. It shows a section of the bulla ethmoidalis, which is very large, extending downward and forward, partially closing the infundibulum and the hiatus semilunaris.

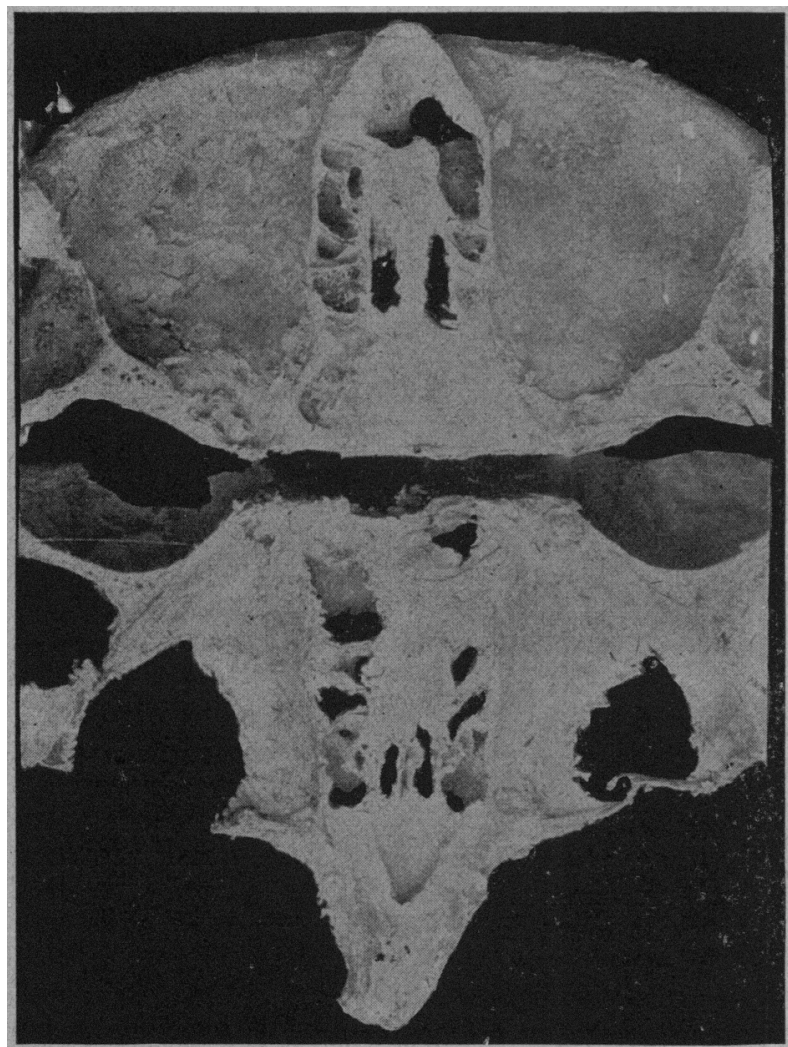

Figure 25.

Figure 23 is from the same specimen; figure $23 a$ being the same as that at the right in the last, figure $23 b$ being the other half of the section. They show a bulla ethmoidalis cut through. There is also

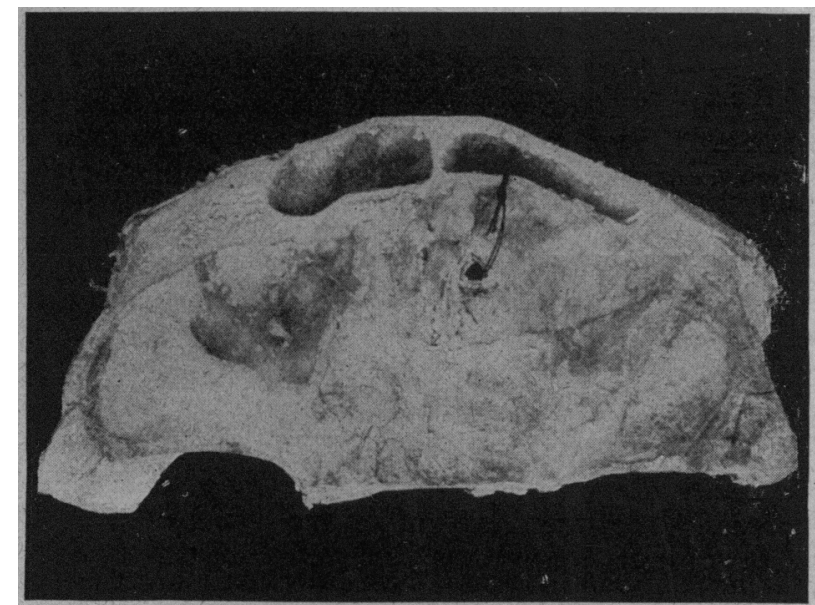

Figure 26.

a condition sometimes met with, particularly when the hard palate is unusually flat, the floor of the nose, instead of being horizontal, is depressed about the middle, giving a concavity to the floor of the nose.

Figure 24 shows a transverse section through the frontal sinuses; from one of which there has been no foramen of exit.

Figure 25. Same subject; the section made one

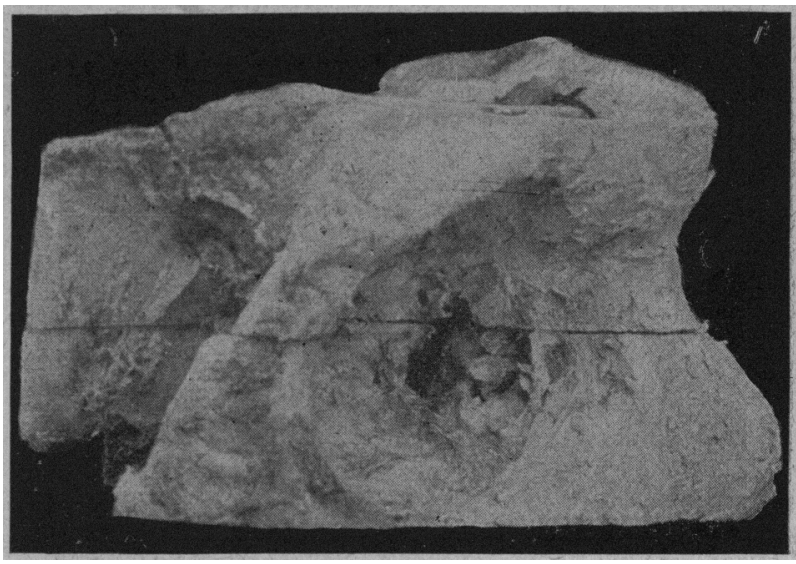

Figure $2 \pi$.

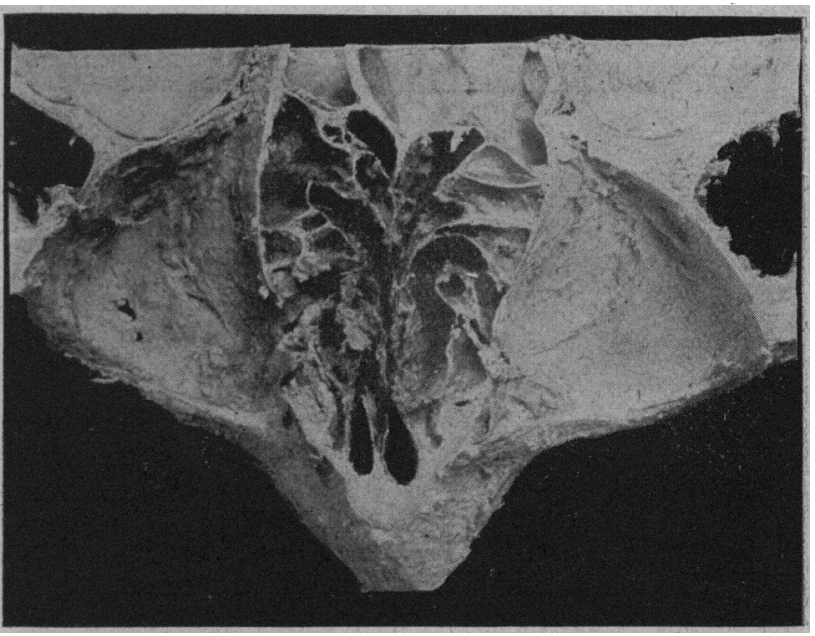

Figure $28 a$

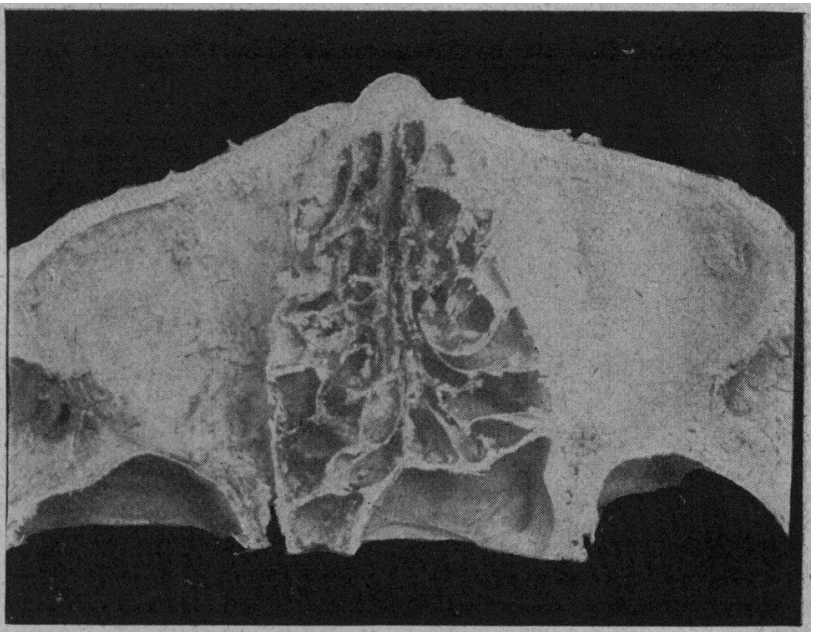

Figure $28 b$.

inch below the former, shows the downward excavation which has occurred in the occluded sinus. In the lower picture the surface of the specimen is shown, the excavation extending into the nasal bone. A 
marked irregularity of the ethmoidal cells of the two sides will also be observed.

Figure 26 is also a specimen of unilateral occlusion. This section exhibits the floor of the brain case. It appears as though the secretion of the occluded sinus had formed a retention cyst, the pressure of which has caused perforation of the brain case, the crista galli being bent down almost flat by the growth of the cyst. Unfortunately, I have no antemortem, or clear postmortem notes of the cases. I should expect, however, that the patient presented cerebral symptoms.

Figure 27. Same specimen; shows the effect of the encroachment of the cyst upon the inner orbital wall, which is badly broken down.

Figure $28^{\circ}$ shows a horizontal section through the ethmoidal cell, nasal fossæ, etc., at a point indicated in the last figure (No. 27).

These slides are presented with a double object; first, to show what limited reliance is to be placed upon ordinary text-book anatomy of these parts; second, to demonstrate that what are called abnormalities of structure in these parts are far from uncommon.

\section{DO VIVISECTORS INFLICT UNNECES- SARY SUFFERING IN THEIR INVESTIGATIONS?}

BY E. STUVER, M.S., M.D., Pr.D.

Member American Medical Associaticn; Colorado State Medical Society; International Medical Congress Berlin, etc. RAWLINS, WYOMING.

About July 18, 1897, there was published in the Rocky Mountain News, an article by E. K. Whitehead, secretary of the Colorado Humane Society, followed on August 30 by another. In these articles the scientific experimenters of the world are directly charged with brutal, inhuman, wanton and cruel conduct toward animals, in carring out their experiments and investigations. Physicians are charged with being participators or accomplices in these so-called atrocities, and it is claimed that no real advance in medical knowledge, which could not have been made without it, has followed as a result of vivisection.

The charge that physicians, without sufficient th cause, sanction wanton or cruel treatment, or animal mutilations and sufferings which are unnecessary, is a gratuitous insult to a profession animated by the most self-sacrificing and humane instincts of any class of people in the world, a profession which has done more to alleviate human suffering, stay the devastations of plague, diseases and death, to discover and demonstrate the laws of health and causes of diseases, and raise mankind to a higher and better plane, in short to advance civilization, than all other influences combined.

When these facts are appreciated I believe all fair minded people will concede that the medical profes. sion is animated by noble and disinterested motives; that its vivisections and all other investigations and experiments are made in the interests of science, truth and humanity, and not, as has been charged, for the mere sake of performing experiments.

The object of all these scientific investigations is to find out the causes of things, and it was only when inductive science came and put intelligently planned experiments in the place of haphazard experience that a single advance was made. (A. M. S. B. April 10, 1897, p. 318.) On the principles and truths thus discovered by experimental investigations, the splendid results of our modern scientific knowledge and inven. tions, our progress in medicine, surgery and sanitary science alnost entirely depends.

We who live under the benign influences of modern sanitary surroundings, and in the clear light of the laws of health already demonstrated by vivisection experiments, can not realize the benefits we enjoy until we draw aside the dark pall of time that covers the results of thousands of years of empirical experience. Do this and we behold plague and pestilence sweeping over the land, leaving desolation and death in their track. Here we see cities converted into charnel houses, the streets covered with dead bodies, and not enough well to care for the sick and dying; there we behold uncoffined corpses rolled into great trenches, or left as food for ravening animals, or to pollute the atmosphere. We, who enjoy the immunity afforded by vaccination, can scarcely believe that such ravages were caused by smallpox in London as are so graphically described by the historian Macaulay, who informs us that it was a rare thing at one time to find a person in that great city not disfigured or marked by the dread disease. Experimental investigation has stamped out smallpox, except in communities ruled by antivaccination cranks, and diphtheria appears to be in a fair way to share a similar fate. Still, we are challenged by the hypercritical, hypersensitive and I might say, hysterical advocates of a measure which is designed to be the entering wedge of a system of espionage, surveillance and obstruction to experiments made on living animals; a system that would place the lives of a few dogs, cats, guinea pigs, or other lower animals above science, truth and the lives of thousands of human beings, for however much some of the advocates of the pending measure may try to conceal their real intentions, yet their avowed purpose, as boldly announced by others, is the entire suppression of all vivisection. We are challenged by these misguided people to give specific instances of the benefits arising from vivisection experiments. While anything I may say, probably will not influence radical antivivisectionists, because, as some one has said, " some human beings would deny the multiplication table and the axioms of geometry, if they came in the way of their sentiments," still I hope that fathers and mothers who desire to see their children grow up into strong, healthy and happy men and women, will impartially consider the facts of history and lend their assistance in securing the desired results.

By the vivisections of Malpighi, Waller and Cohnheim we learned how blood nourishes the tissues; by the animal experiments of Aselli and Pecquet, how the chyle is carried into the blood. The processes of intestinal digestion were revealed by the vivisections of Hunter, Magendie and others. Sir Charles Bell and Magendie in the same way discovered the difference between the motor and sensory functions of the spinal nerves, and the experiments of Ferrier and a host of others have so illumined the physiology of the brain and localized its functions that many things which were dark and mysterious a few years ago are now as clear as the noon. day sun. The results of the experiments of Pasteur caused Lister to investigate the influence of antisepsis in the treatment of wounds. This has led to our modern antiseptic treatment which has saved thousands of lives and untold suffering, besides bringing surgery to a degree of per- 